\title{
Electroosmotic dewatering of cellulose nanocrystals
}

\author{
Jonas Wetterling · Karin Sahlin • Tuve Mattsson • Gunnar Westman • \\ Hans Theliander (i)
}

Received: 19 December 2017/ Accepted: 27 February 2018/Published online: 6 March 2018

(C) The Author(s) 2018. This article is an open access publication

\begin{abstract}
One of the main challenges for industrial production of cellulose nanocrystals is the high energy demand during the dewatering of dilute aqueous suspensions. It is addressed in this study by utilising electroosmotic dewatering to increase the solid content of suspensions of cellulose nanocrystals. The solid content was increased from 2.3 up to $15.3 \mathrm{wt} \%$, i.e. removal of more than $85 \%$ of all the water present in the system, at a much lower energy demand than that of thermal drying. Increasing the strength of the electric field increased not only the dewatering rate but also the specific energy demand of the dewatering operation: the electric field strength used in potential industrial applications is thus a trade-off between the rate of dewatering and the energy demand. Additionally, it was found that high local current intensity had the potential of degrading cellulose nanocrystals in contact with the anode. The maximum strength of the electric field applied should therefore be limited
\end{abstract}

J. Wetterling $\cdot$ K. Sahlin · T. Mattsson .

G. Westman · H. Theliander $(\bowtie)$

Department of Chemistry and Chemical Engineering,

Chalmers University of Technology, 41296 Gothenburg,

Sweden

e-mail: hanst@chalmers.se

J. Wetterling $\cdot$ K. Sahlin · T. Mattsson .

G. Westman $\cdot$ H. Theliander

Wallenberg Wood Science Center, The Royal Institute of

Technology, Chalmers University of Technology,

10044 Stockholm, Sweden depending on the equipment design and the suspension conditions.

Keywords Cellulose nanocrystals - Nanocellulose · Electroosmotic dewatering · Solid-liquid separation · Energy demand

\section{Introduction}

Production of cellulose nanocrystals and nanofibrillated cellulose is gathering significant interest amongst researchers as these materials combine mechanical strength and toughness with a low density, biodegradability and renewability (Siró and Plackett 2010). Applications in which they may be used are therefore plentiful, either as components in composite materials or in films and foams (Isogai 2013). However, large-scale production of materials based on cellulose nanocrystals requires the development of processing techniques that are industrially viable (Oksman et al. 2016). Cellulose nanocrystals are typically produced and processed in aqueous suspensions, so one of the main challenges facing the largescale production of materials from cellulose nanocrystals is therefore to obtain an energy-efficient solidliquid separation.

Production of cellulose nanocrystals through acid hydrolysis typically results in the formation of 
suspensions with a low solid content. On a laboratory scale, centrifugation is often used to increase the solid content during washing of the particles, however, the solid content is typically remains in the range 0.2-3 wt\% (e.g. Ávila Ramírez et al. 2017; Bai et al. 2009; Cranston and Gray 2006; Kedzior et al. 2016). Many industrial applications require that this solid content is increased and different drying methods, such as thermal, freeze and supercritical drying, can be used to obtain a dry material (Peng et al. 2012, 2013). However, these techniques are associated with significant energy demands. Dewatering will therefore have a great influence on the energy demand of industrial production of cellulose nanocrystals. A rough estimate of the energy demand for drying can be made from the amount of water that needs to be separated: the heat of evaporation of water is $2260 \mathrm{~kJ} / \mathrm{kg}$ at atmospheric pressure and, assuming an initial solid content of the suspension of $2 \mathrm{wt} \%$, the resulting energy demand would be about $110 \mathrm{MJ} / \mathrm{kg}$ of dry cellulose nanocrystals. Increasing the solid content of the suspension before drying could therefore decrease the energy demand in large-scale production to a very large extent.

The solid content is often increased by a mechanical dewatering operation such as filtration as a precursor to drying operations. However, the large specific surface area of cellulose nanocrystals means that the filtration resistance of the material is very high; the demands this makes on operation time and/or equipment size therefore limits the use of filtration. Electroosmotic dewatering is an assisted filtration technique that can be used to increase the solid content of suspensions of materials with charged surfaces (Iwata et al. 2013; Mahmoud et al. 2010). It has proved to be useful in increasing the solid content of cellulosic materials with high specific surface areas (Wetterling et al. 2017a), such as microfibrillated cellulose suspensions (Heiskanen et al. 2014), and has also shown potential for use in the dewatering of both biopolymers (Gözke and Posten 2010; Hofmann et al. 2006; Hofmann and Posten 2003) and hydrogels (Tanaka et al. 2014). Using electroosmotic dewatering prior to drying can decrease the total energy demand of the dewatering operation (Larue et al. 2006; Loginov et al. 2013; Mahmoud et al. 2011) and is therefore also attracting significant research interest in the treatment of wastewater sludge (Citeau et al. 2012; Mahmoud et al. 2011; Olivier et al. 2015).
In this study, the use of electroosmotic dewatering to increase the solid content of suspensions of cellulose nanocrystals is investigated. The manner in which the strength of the applied electric field influences the dewatering operation is studied with regard to the dewatering rate as well as the specific energy demand.

\section{Background}

Electroosmotic dewatering involves an electric field applied across a suspension of charged particles. Particles with a negative surface charge experience an electrophoretic force in the direction of the anode. The electric field also induces a movement of the fluid in the direction of the cathode, thereby providing a driving force for separation (Kobayashi et al. 1979; Yukawa et al. 1971, 1976). The electroosmotic flow rate during the electrofiltration experiments can be described by the Helmholtz-Smoluchowski equation (Hiemenz and Rajagopalan 1997) thus:

$Q_{e o}=-\frac{D \varepsilon_{0} \zeta}{\mu}\left(1-\phi_{c}\right) A E$

where $Q_{e o}$ is the electroosmotic flow rate, $D$ the dielectric constant of the liquid phase, $\varepsilon_{0}$ the permittivity of vacuum, $\zeta$ the zeta-potential, $\mu$ the fluid viscosity, $\phi_{c}$ the filter cake solidosity, $A$ the crosssectional area of the filter cell and $E$ the strength of the electric field.

For cellulose nanocrystals in suspensions of low ionic strength, the dimension of the solid particles may be of the same order of magnitude as the Debye length. Surface conduction of the solid particles may therefore have a significant influence on the electrical conductivity of the system, and would need to be accounted for when describing the electroosmotic flow (Delgado et al. 2007). By assuming flow in cylindrical capillaries, an expression accounting for the surface conductivity is given in Eq. (2) (Rice and Whitehead 1965):

$Q_{e o}=-\frac{D \varepsilon_{0} \zeta}{\mu}\left(1-\phi_{c}\right) A E[1-G(\kappa a)]$

where $\kappa$ is the reciprocal Debye length and $a$ is the radius of the capillary. $G(\kappa a)$ is defined by:

$G(\kappa a)=\frac{2 I_{1}(\kappa a)}{\kappa a I_{0}(\kappa a)}$ 
where $I_{0}$ and $I_{1}$ are the zero and first order modified Bessel functions of the first kind, respectively. The electroosmotic dewatering rate decrease drastically due to surface conduction when $\kappa a<10$, i.e. for small particles and suspensions with a low conductivity in the liquid phase.

In addition to the electroosmotic force, the electric field may result in electrolysis reactions at the electrodes that influence the suspension conditions. The main electrolysis reactions at the anode are (Lockhart 1983; Mahmoud et al. 2010):

$2 \mathrm{H}_{2} \mathrm{O} \rightarrow \mathrm{O}_{2}+4 \mathrm{H}^{+}+4 e^{-}$

$M \rightarrow M^{n+}+n e^{-}$

where $M$ is the material of the electrode. The anodes used for electrofiltration are often constructed from titanium meshes coated by either mixed metal oxides (Citeau et al. 2012; Raats et al. 2002) or noble metals (Rabie et al. 1994; Saveyn et al. 2006) in order to prevent corrosion (Larue et al. 2003). The electrolysis reactions at the cathode are:

$$
\begin{aligned}
& 2 \mathrm{H}_{2} \mathrm{O}+2 e^{-} \rightarrow 2 \mathrm{OH}^{-}+\mathrm{H}_{2} \\
& M^{n+}+n e^{-} \rightarrow M
\end{aligned}
$$

\section{Experimental}

Preparation of the cellulose nanocrystals

Suspensions of cellulose nanocrystals were prepared by acid hydrolysis of a commercially available microcrystalline cellulose (Avicel $\left.{ }^{\circledR} \mathrm{PH}-101\right)$ using a procedure described in an earlier publication (Sahlin et al. 2017) adapted from Hasani et al. (2008). Hydrolysis of $500 \mathrm{~g}$ microcrystalline cellulose was performed using $4.37 \mathrm{dm}^{3}$ of $64 \%$ w/w sulphuric acid at $45{ }^{\circ} \mathrm{C}$ for $2 \mathrm{~h}$ under continuous stirring, after which the suspension was diluted with deionised water to quench the reaction. Excess acid was removed through dialysis against deionised water until the conductivity of the effluent was stable, below $5 \mu \mathrm{S} / \mathrm{cm}$. The suspension was then sonicated using a Vibracell Sonicator (Sonics and Materials Inc., Danbury, CT) at $40 \%$ output for $6 \times 7$ min until a colloidal dispersion of cellulose nanocrystals was obtained.
The prepared suspension of cellulose nanocrystals had a cellulose content of $2.3 \mathrm{wt} \%$, a $\mathrm{pH}$ of 3.3 and a conductivity of $1950 \mu \mathrm{S} / \mathrm{cm}$. The prepared suspension was stable, neither precipitate nor supernatant was observed after centrifugation $(4000 \times g$ for $15 \mathrm{~min})$.

Characterisation of the cellulose nanocrystals

Cellulose nanocrystals produced using the same setup and procedure as used in this study have been characterised extensively in a previous publications; the average dimensions of the dispersed cellulose nanocrystals were determined as being $\sim 300 \mathrm{~nm} \times$ $7 \mathrm{~nm}$ by atomic force microscopy (Börjesson et al. 2018; Moberg et al. 2017).

The use of sulphuric acid in the hydrolysis of cellulose introduces negatively charged sulphate halfester groups on the surface of the cellulose nanocrystals and affects the charge of the particle surfaces (Beck-Candanedo et al. 2005). The content of sulphate esters was determined by conductometric titration with $0.01 \mathrm{M}$ sodium hydroxide at a cellulose content of $0.1 \mathrm{wt} \%$ in the suspension. The content of sulphate was determined at $350 \mu \mathrm{mol} / \mathrm{g}$ cellulose. The $\zeta$ potential of the cellulose nanocrystals was measured under controlled conditions using a Zetasizer Nano ZS (Malvern Instruments). Samples were diluted to a solid content of $0.05 \mathrm{wt} \%$ and the $\mathrm{pH}$ adjusted to 3.5, followed by ion exchange (Dowex Marathon MR-3 hydrogen and hydroxide form) and subsequent removal of the resin beads through filtration. Repeated measurements were performed at $25^{\circ} \mathrm{C}$ and the $\zeta$ potential was determined as $-72( \pm 2) \mathrm{mV}$.

Cellulose nanocrystals were examined after electroosmotic dewatering using Fourier Transform Infrared (FT-IR) spectroscopy (PerkinElmer Frontier) with an Attenuated Total Reflectance (ATR) sampling accessory (PIKE Technologies GladiATR). Samples were measured with a resolution of $4 \mathrm{~cm}^{-1}$ and 32 scans; all spectra were corrected against air and normalised to the highest band.

\section{Electroosmotic dewatering equipment}

The experimental equipment used for the electroosmotic dewatering experiments has been described in a previous study on local filtration properties during electro-assisted filtration (Wetterling et al. 2017b), see Fig. 1. The dewatering cell is cylindrical, with an 


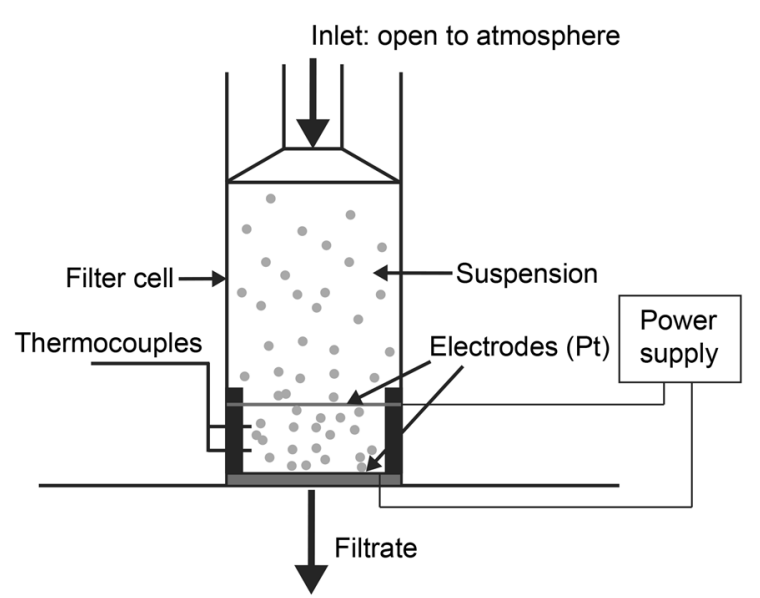

Fig. 1 Schematic diagram of the equipment used in the electroosmotic dewatering experiments

internal diameter of $60 \mathrm{~mm}$ and a height of $175 \mathrm{~mm}$. The bottom of the cell consists of a perforated plastic plate that supports the filter medium. A hydrophilic polyethersulphone membrane $\left(\right.$ Supor $\left.^{\circledR}\right)$ with a nominal pore size of $0.1 \mu \mathrm{m}$, according to the product specifications, was used as the filter medium for all dewatering experiments. The filtrate was collected and the weight of the filtrate was recorded every $2 \mathrm{~s}$ during the dewatering operation. The temperature inside the filter cell was measured using two PFA-coated K-type thermocouples located 5 and $20 \mathrm{~mm}$, respectively, from the filter medium.

The dewatering cell is equipped with two platinum electrodes connected to a DC power supply (EA-PSI 5200-02 A, Elektro-Automatik). An expanded platinum mesh (Unimesh 300) is used as the cathode and is placed beneath the filter medium. The anode, which is a mesh made of platinum wire of diameter $0.127 \mathrm{~mm}$, has $10 \mathrm{~mm}$ square openings. The anode is placed inside the dewatering cell resting on a support rack; the internal diameter of the cell is thus decreased to $50 \mathrm{~mm}$ for the $30 \mathrm{~mm}$ closest to the filter medium. The electrode separation is constant at $25 \mathrm{~mm}$; a constant voltage is applied during each dewatering experiment.

In the region between the electrodes an electrophoretic force acts on the cellulose nanocrystals in the direction of the anode, whereas water is transported by electroosmotic flow through the filter cell and collected beneath the cathode. As water is being removed from the system through the filter medium, the suspension enters the space between the electrodes through the openings in the anode mesh. The volume of the dewatering cell above the anode thus acts as a reservoir, feeding suspension into the volume between the electrodes.

\section{Results and discussion}

The average solid content between the electrodes during electroosmotic dewatering of a suspension of cellulose nanocrystals are shown in Fig. 2 for an applied electric field strength of $5 \mathrm{~V} / \mathrm{cm}$. The solid content of the cellulose nanocrystals increased from 2.3 to $15.3 \mathrm{wt} \%$. Electroosmotic dewatering was thus used to remove more than $85 \%$ of all water from the initial suspension. Following electroosmotic dewatering, the cellulose nanocrystals were recovered in the form of a viscous gel and could be readily re-dispersed after dilution.

The influence of the strength of the electric field on the dewatering rate and the specific energy demand of the operation is discussed in the following sections.

Strength of the electric field

The influence of the strength of the applied electric field on the electroosmotic dewatering rate is shown in Fig. 3. The dewatering operation is strongly dependent on the electrical conductivity of the system; the current intensities required to maintain the constant electric field strengths are given in Fig. 4.

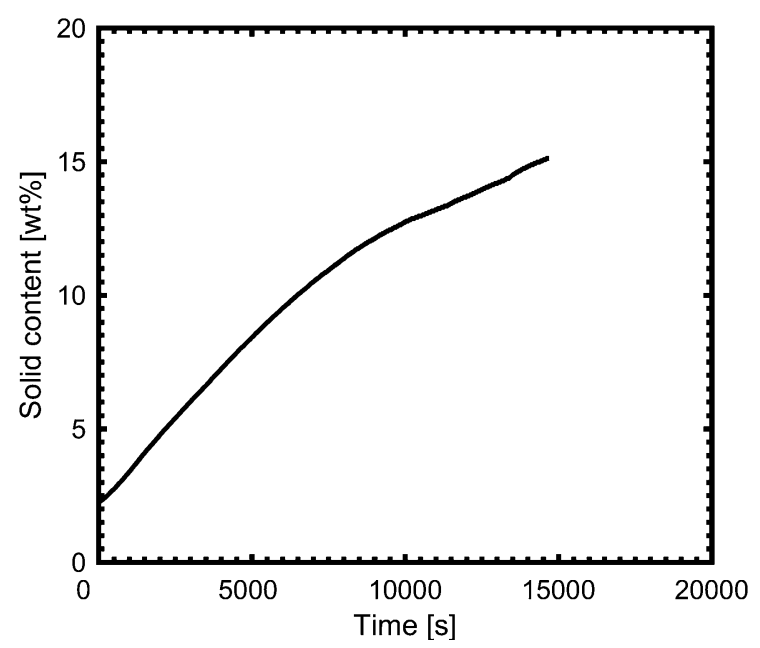

Fig. 2 Average solid content between the electrodes during electroosmotic dewatering with an applied electric field of $5 \mathrm{~V} /$ $\mathrm{cm}$ 


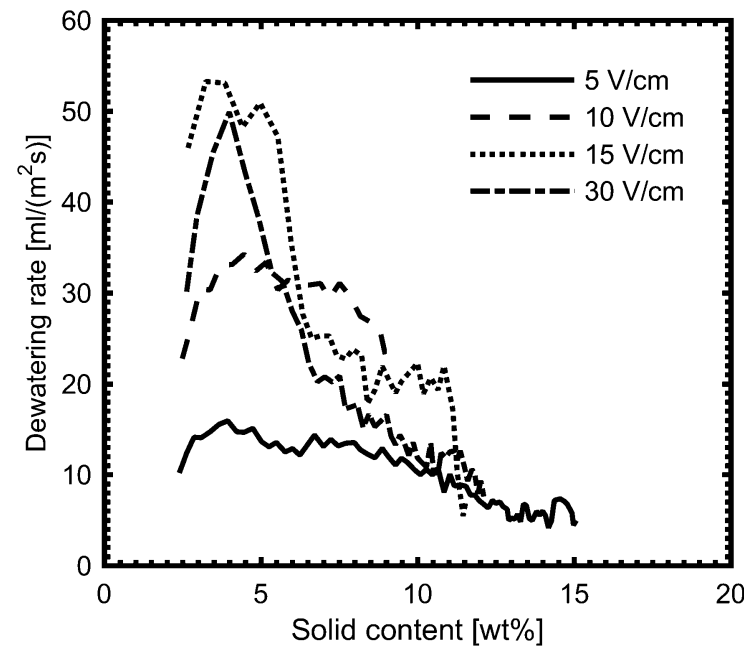

Fig. 3 Electroosmotic dewatering rate of cellulose nanocrystals when different electric field strengths are applied

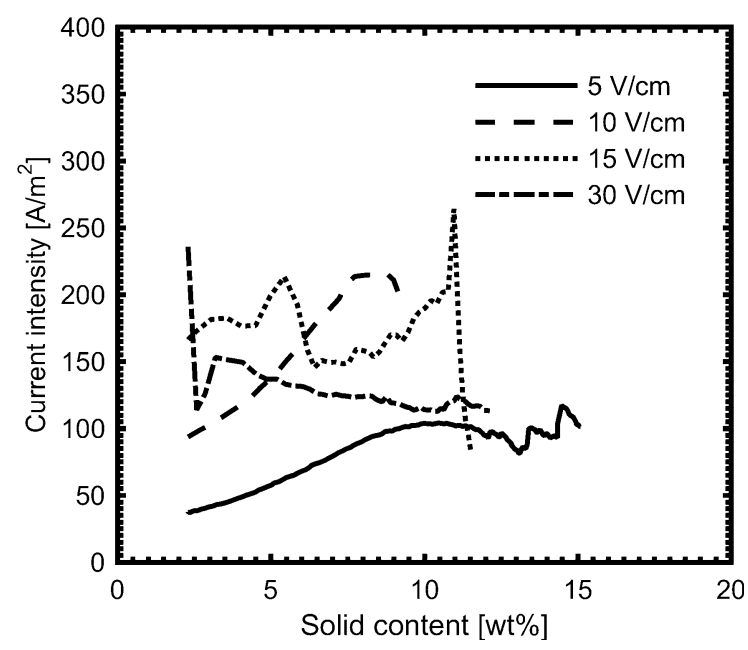

Fig. 4 Current intensity during electroosmotic dewatering at different constant applied voltages

Figure 3 shows that when an electric field of $5 \mathrm{~V} /$ $\mathrm{cm}$ was applied, the dewatering rate was fairly stable up to a solid content of $10 \mathrm{wt} \%$. Doubling the strength of the applied electric field to $10 \mathrm{~V} / \mathrm{cm}$ resulted in a doubled dewatering rate, as would be expected according to the Helmholtz-Smoluchowski equation. At these applied electric field strengths, Fig. 4 shows that the current intensity increased during the dewatering operation: an effect of the increasing electrical conductivity of the system. The electrical conductivity increased due to a combination of the accumulation of ionic electrolysis products between the electrodes and the increasing content of cellulose nanocrystals enhancing the contribution of surface conductivity.

As the average solid content between the electrodes approached, or surpassed, $10 \mathrm{wt} \%$ both the dewatering rate and the current intensity decreased for the experiments performed at 5 and $10 \mathrm{~V} / \mathrm{cm}$. A possible explanation for this effect could be that the solid gel structure of the cellulose nanocrystals at these solid contents decreases the flow of the suspension through the anode mesh, thereby resulting in desiccation of the cellulose nanocrystals that are in contact with the anode. Desiccation would result in a decrease in electrical conductivity and cause a high voltage drop close to the anode: the strength of the electric field in the rest of the filter cell would be lowered and thus reduce the driving force for electroosmotic flow. Further studies, using anodes of different designs and various cell configurations, are required to investigate this behaviour.

At an applied electric field of $15 \mathrm{~V} / \mathrm{cm}$ the relation between the initial dewatering rate in Fig. 3 and the rates at 5 and $10 \mathrm{~V} / \mathrm{cm}$ was as expected, according to the Helmholtz-Smoluchowski equation: a linear dependence on the strength of the electric field applied. For an applied field of $15 \mathrm{~V} / \mathrm{cm}$, however, the dewatering rate decreased at a solid content of about $6 \mathrm{wt} \%$ to a rate lower than that obtained for $10 \mathrm{~V} / \mathrm{cm}$. The current intensity in Fig. 4 increased with the solid content in a similar manner as for the lower electric field strengths up until $6 \mathrm{wt} \%$. However, when the current intensity approached $220 \mathrm{~A} / \mathrm{m}^{2}$, the intensity of the current decreased rapidly, indicating an increase in electrical resistance. It should be noted here that the intensity of the local current at the anode wire was significantly higher, due to the design of the electrode employed. Dissection of the gel of cellulose nanocrystals obtained after electroosmotic dewatering showed the formation of a black layer, possibly char, in the immediate proximity of the anode wire. A reasonable explanation for the increasing electrical resistance is thus the formation of the char layer. The char layer and the suspension of cellulose nanocrystals present between the electrodes may then be considered as being two electrical resistances coupled in series. A char layer of high electrical resistance will give a significant voltage drop close to the anode and decrease the strength of the electric field in the 
remainder of the filter cell which, in turn, will decrease the driving force of electroosmotic flow.

The rate of dewatering at an applied electric field of $30 \mathrm{~V} / \mathrm{cm}$, shown in Fig. 3, was found to be lower than that at $15 \mathrm{~V} / \mathrm{cm}$. The current intensity, Fig. 4, was observed to drop rapidly during the early stages of the dewatering operation. Experiments terminated at various stages during the dewatering operation showed that a char layer was formed by the anode at the start of the dewatering experiments for this electric field strength. The photograph in Fig. 5a depicts the cellulose nanocrystals after electroosmotic dewatering at $30 \mathrm{~V} / \mathrm{cm}$; a black layer is visible where the cellulose nanocrystals were in contact with the anode wire. For the purpose of comparison, the image in Fig. 5b shows that no signs of a blackened layer could be observed

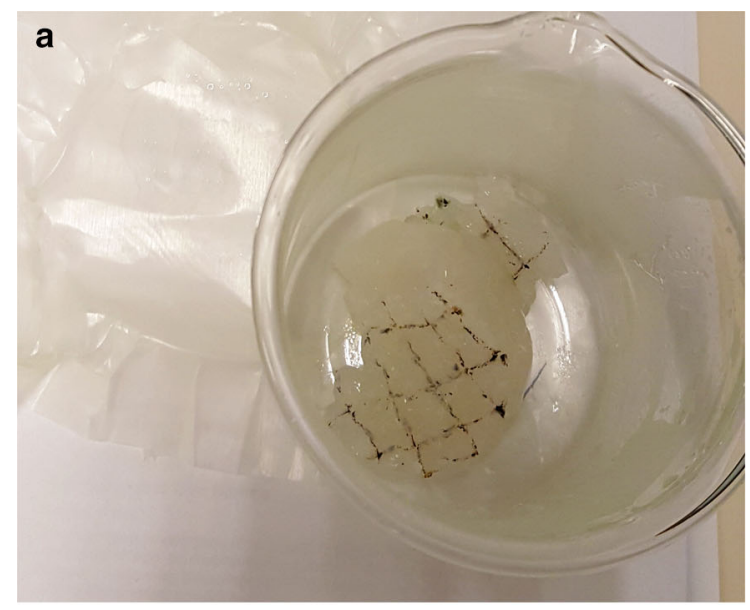

\section{b}

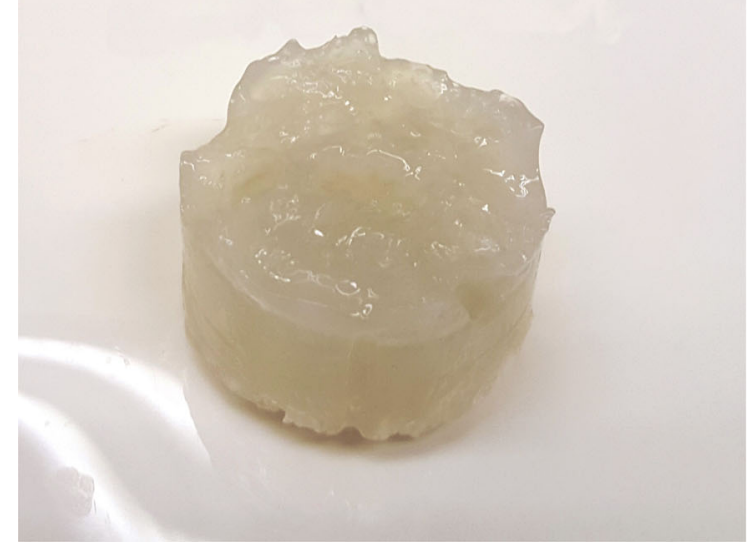

Fig. 5 a Image of cellulose nanocrystals with an average solid content of $10.8 \mathrm{wt} \%$, after electroosmotic dewatering at $30 \mathrm{~V} /$ $\mathrm{cm}$. b Image of cellulose nanocrystals with an average solid content of $15.3 \mathrm{wt} \%$ after electroosmotic dewatering at $5 \mathrm{~V} / \mathrm{cm}$ after electroosmotic dewatering at $5 \mathrm{~V} / \mathrm{cm}$. The char layer and the cellulose nanocrystals were analysed with ATR-IR and the spectra are given in Fig. 6. These spectra indicate chemical changes in the cellulose nanocrystals that are suggestive of dehydration: new peaks are observed in the range $1600-1740 \mathrm{~cm}^{-1}$, attributed to formation of double bonds and carbonyls, and there is a decrease in intensity at $990 \mathrm{~cm}^{-1}$, corresponding to $\mathrm{C}-\mathrm{O}$ skeletal vibrations of the secondary alcohols. These effects are in agreement with the changes observed during char formation of cellulose through pyrolysis (Pastorova et al. 1994).

\section{Specific energy demand}

The specific energy demands for electroosmotic dewatering at different electric field strengths are shown in Fig. 7. The energy demand increased with the strength of the applied electric field as an increased current intensity is required to maintain the constant voltage. As the energy demand increases with the strength of the electric field applied, the optimal strength for electroosmotic dewatering is therefore a compromise between the specific energy demand and the rate of dewatering. Increasing the intensity of the current results in increased ohmic heating as well as increased formation of electrolysis products. The temperature in the filter cell during electroosmotic dewatering is shown in Fig. 8. The ohmic heating increased with the strength of the electric field applied, with only a limited temperature rise being observed at 5 and $10 \mathrm{~V} / \mathrm{cm}$.

The energy demand of the electroosmotic dewatering of suspensions of cellulose nanocrystals using the experimental setup in this study was only a fraction of that required for thermal drying: for reference, the heat of evaporation of water at atmospheric pressure is $0.63 \mathrm{~kW} \mathrm{~h} / \mathrm{kg}$. The energy demand of the electroosmotic dewatering operation is, however, influenced by the electrical conductivity of the suspension. The energy demand of systems with a high degree of electrical conductivity, e.g. suspensions of high ionic strength, will increase as the intensity of the current required to maintain the electric field increases (Wetterling et al. 2017a). Moreover, the energy demand will also be influenced by the electrode separation as this influences the electrical resistance of the system and the strength of the electric field for any given voltage that is applied. 
Fig. 6 ATR-IR spectra of the cellulose nanocrystals and the black layer formed at the anode during electroosmotic dewatering at an applied electric field of $30 \mathrm{~V} / \mathrm{cm}$

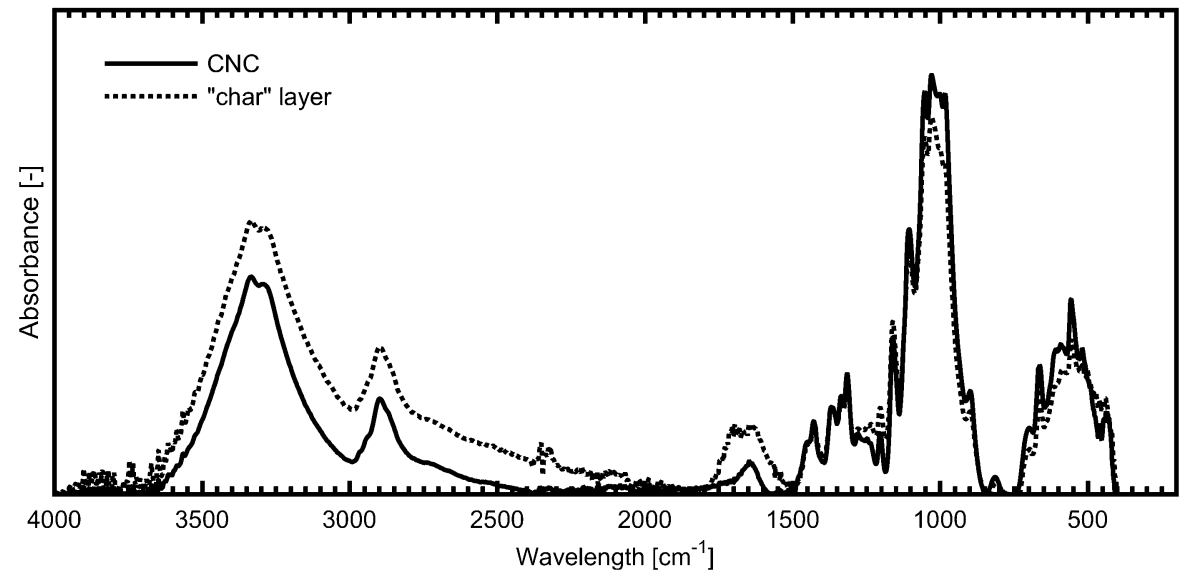

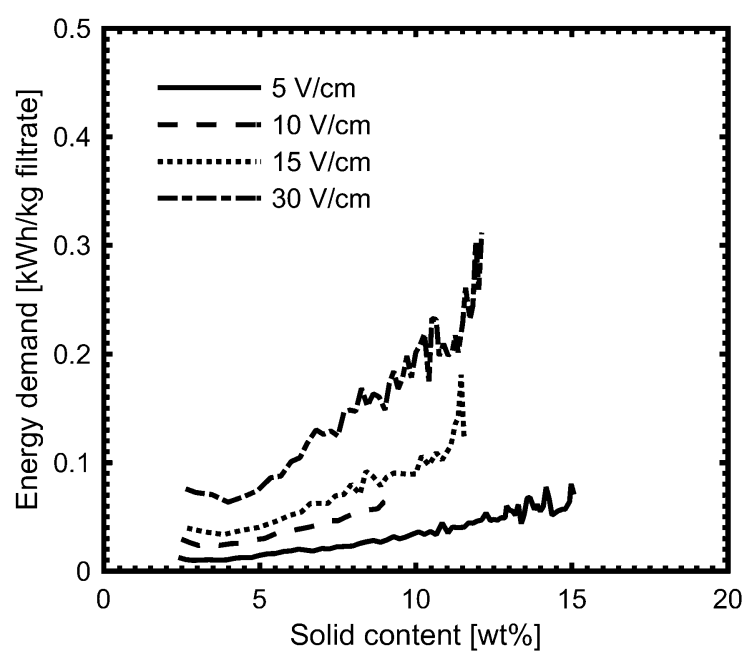

Fig. 7 Specific energy demands required for electroosmotic dewatering at various applied electric fields

\section{Conclusions}

- Electroosmotic dewatering can be used to increase the solid content in suspensions of cellulose nanocrystals. Using the experimental equipment presented in this study the solid content of a suspension of cellulose nanocrystals was increased from 2.3 to $15.3 \mathrm{wt} \%$ : this corresponds to the removal of more than $85 \%$ of all water present in the initial suspension at a very low energy demand compared to thermal drying.

- Increasing the strength of the electric field increased the rate of dewatering, but also increased the energy demand of the dewatering operation.

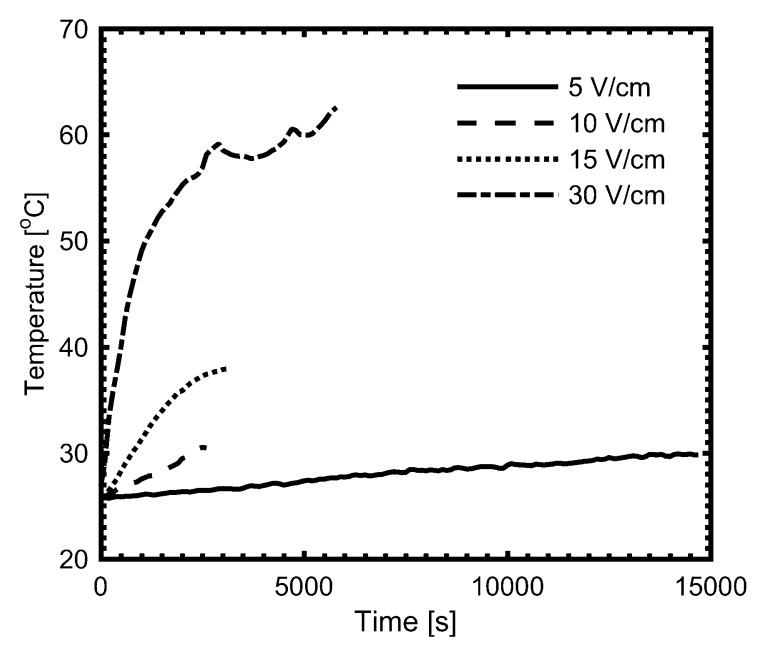

Fig. 8 Temperature during electroosmotic dewatering at various applied electric fields, measured $5 \mathrm{~mm}$ from the filter medium

- Increasing the electric field strength above $10 \mathrm{~V} /$ $\mathrm{cm}$ for the experimental equipment and suspension of cellulose nanocrystals used in this study gave had no positive effect on the dewatering rate yield due to a layer of degraded cellulose formed in direct contact with the anode.

Acknowledgments This study was performed within the framework of the Wallenberg Wood Science Center, and the financial support of the Knut and Alice Wallenberg Foundation is gratefully acknowledged. Maria Gunnarsson is thanked for her assistance with the IR spectroscopy.

Open Access This article is distributed under the terms of the Creative Commons Attribution 4.0 International License (http:// creativecommons.org/licenses/by/4.0/), which permits 
unrestricted use, distribution, and reproduction in any medium, provided you give appropriate credit to the original author(s) and the source, provide a link to the Creative Commons license, and indicate if changes were made.

\section{References}

Ávila Ramírez JA, Fortunati E, Kenny JM, Torre L, Foresti ML (2017) Simple citric acid-catalyzed surface esterification of cellulose nanocrystals. Carbohydr Polym 157:1358-1364. https://doi.org/10.1016/j.carbpol.2016.11.008

Bai W, Holbery J, Li K (2009) A technique for production of nanocrystalline cellulose with a narrow size distribution. Cellulose 16:455-465. https://doi.org/10.1007/s10570009-9277-1

Beck-Candanedo S, Roman M, Gray DG (2005) Effect of reaction conditions on the properties and behavior of wood cellulose nanocrystal suspensions. Biomacromol 6:1048-1054. https://doi.org/10.1021/bm049300p

Börjesson M, Sahlin K, Bernin D, Westman G (2018) Increased thermal stability of nanocellulose composites by functionalization of the sulfate groups on cellulose nanocrystals with azetidinium ions. J Appl Polym Sci 135:45963. https://doi.org/10.1002/app.45963

Citeau M, Olivier J, Mahmoud A, Vaxelaire J, Larue O, Vorobiev E (2012) Pressurised electro-osmotic dewatering of activated and anaerobically digested sludges: electrical variables analysis. Water Res 46:4405-4416. https://doi. org/10.1016/j.watres.2012.05.053

Cranston ED, Gray DG (2006) Morphological and optical characterization of polyelectrolyte multilayers incorporating nanocrystalline cellulose. Biomacromol 7:2522-2530. https://doi.org/10.1021/bm0602886

Delgado AV, González-Caballero F, Hunter RJ, Koopal LK, Lyklema J (2007) Measurement and interpretation of electrokinetic phenomena. J Colloid Interface Sci 309:194-224. https://doi.org/10.1016/j.jcis.2006.12.075

Gözke G, Posten C (2010) Electrofiltration of biopolymers. Food Eng Rev 2:131-146. https://doi.org/10.1007/s12393010-9016-2

Hasani M, Cranston ED, Westman G, Gray DG (2008) Cationic surface functionalization of cellulose nanocrystals. Soft Matter 4:2238-2244. https://doi.org/10.1039/B806789A

Heiskanen I, Backfolk K, Kotilainen A, Gaidelis V, Sidaravicius J (2014) Process for treating microfibrillated cellulose and microfibrillated cellulose treated according to the process. US Patent 2014/0088301 A1

Hiemenz PC, Rajagopalan R (1997) Principles of colloid and surface chemistry, vol 14. CRC Press, Boca Raton, pp 543-553

Hofmann R, Posten C (2003) Improvement of dead-end filtration of biopolymers with pressure electrofiltration. Chem Eng Sci 58:3847-3858. https://doi.org/10.1016/S00092509(03)00271-9

Hofmann R, Käppler T, Posten C (2006) Pilot-scale press electrofiltration of biopolymers. Sep Purif Technol 51:303-309. https://doi.org/10.1016/j.seppur.2006.01.015
Isogai A (2013) Wood nanocelluloses: fundamentals and applications as new bio-based nanomaterials. J Wood Sci 59:449-459. https://doi.org/10.1007/s10086-013-1365-z

Iwata M, Tanaka T, Jami MS (2013) Application of electroosmosis for sludge dewatering-A review. Dry Technol 31: 170-184. https://doi.org/10.1080/07373937.2012.691592

Kedzior SA, Graham L, Moorlag C, Dooley BM, Cranston ED (2016) Poly(methyl methacrylate)-grafted cellulose nanocrystals: one-step synthesis, nanocomposite preparation, and characterization. Can J Chem Eng 94:811-822. https://doi.org/10.1002/cjce.22456

Kobayashi K, Hakoda M, Hosoda Y, Iwata M, Yukawa H (1979) Electroosmotic flow through particle beds and electroosmotic pressure distribution. J Chem Eng Jpn 12:492-494. https://doi.org/10.1252/jcej.12.492

Larue O, Vorobiev E, Vu C, Durand B (2003) Electrocoagulation and coagulation by iron of latex particles in aqueous suspensions. Sep Purif Technol 31:177-192. https://doi. org/10.1016/S1383-5866(02)00182-X

Larue O, Wakeman RJ, Tarleton ES, Vorobiev E (2006) Pressure electroosmotic dewatering with continuous removal of electrolysis products. Chem Eng Sci 61:4732-4740. https://doi.org/10.1016/j.ces.2006.02.006

Lockhart NC (1983) Electroosmotic dewatering of clays, III. Influence of clay type, exchangeable cations, and electrode materials. Colloids Surf 6:253-269. https://doi.org/10. 1016/0166-6622(83)80017-1

Loginov M, Citeau M, Lebovka N, Vorobiev E (2013) Electrodewatering of drilling sludge with liming and electrode heating. Sep Purif Technol 104:89-99. https://doi.org/10. 1016/j.seppur.2012.11.021

Mahmoud A, Olivier J, Vaxelaire J, Hoadley AFA (2010) Electrical field: a historical review of its application and contributions in wastewater sludge dewatering. Water Res 44:2381-2407. https://doi.org/10.1016/j.watres.2010.01. 033

Mahmoud A, Olivier J, Vaxelaire J, Hoadley AFA (2011) Electro-dewatering of wastewater sludge: influence of the operating conditions and their interactions effects. Water Res 45:2795-2810. https://doi.org/10.1016/j.watres.2011. 02.029

Moberg T et al (2017) Rheological properties of nanocellulose suspensions: effects of fibril/particle dimensions and surface characteristics. Cellulose 24:2499-2510. https://doi. org/10.1007/s10570-017-1283-0

Oksman K et al (2016) Review of the recent developments in cellulose nanocomposite processing. Compos A Appl Sci Manuf 83:2-18. https://doi.org/10.1016/j.compositesa. 2015.10.041

Olivier J, Conrardy J-B, Mahmoud A, Vaxelaire J (2015) Electro-dewatering of wastewater sludge: an investigation of the relationship between filtrate flow rate and electric current. Water Res 82:66-77. https://doi.org/10.1016/j. watres.2015.04.006

Pastorova I, Botto RE, Arisz PW, Boon JJ (1994) Cellulose char structure: a combined analytical Py-GC-MS, FTIR, and NMR study. Carbohydr Res 262:27-47. https://doi.org/10. 1016/0008-6215(94)84003-2

Peng Y, Gardner DJ, Han Y (2012) Drying cellulose nanofibrils: in search of a suitable method. Cellulose 19:91-102. https://doi.org/10.1007/s10570-011-9630-z 
Peng Y, Gardner DJ, Han Y, Kiziltas A, Cai Z, Tshabalala MA (2013) Influence of drying method on the material properties of nanocellulose I: thermostability and crystallinity. Cellulose 20:2379-2392. https://doi.org/10.1007/s10570013-0019-z

Raats MHM, van Diemen AJG, Lavèn J, Stein HN (2002) Full scale electrokinetic dewatering of waste sludge. Colloids Surf, A 210:231-241. https://doi.org/10.1016/S09277757(02)00380-1

Rabie HR, Mujumdar AS, Weber ME (1994) Interrupted electroosmotic dewatering of clay suspensions. Sep Technol 4:38-46. https://doi.org/10.1016/0956-9618(94)80004-9

Rice CL, Whitehead R (1965) Electrokinetic flow in a narrow cylindrical capillary. J Phys Chem 69:4017-4024. https:// doi.org/10.1021/j100895a062

Sahlin K, Forsgren L, Moberg T, Bernin D, Rigdahl M, Westman G (2017) Surface treatment of cellulose nanocrystals (CNC): effects on dispersion rheology. Cellulose. https:// doi.org/10.1007/s10570-017-1582-5

Saveyn H, Curvers D, Pel L, De Bondt P, Van der Meeren P (2006) In situ determination of solidosity profiles during activated sludge electrodewatering. Water Res 40:21352142. https://doi.org/10.1016/j.watres.2006.04.003
Siró I, Plackett D (2010) Microfibrillated cellulose and new nanocomposite materials: a review. Cellulose 17:459-494. https://doi.org/10.1007/s10570-010-9405-y

Tanaka T, Fujihara K, Jami MS, Iwata M (2014) Constantcurrent electroosmotic dewatering of superabsorbent hydrogel. Colloids Surf A 440:116-121. https://doi.org/10. 1016/j.colsurfa.2012.10.020

Wetterling J, Jonsson S, Mattsson T, Theliander H (2017a) The influence of ionic strength on the electroassisted filtration of microcrystalline cellulose. Ind Eng Chem Res 56: 12789-12798. https://doi.org/10.1021/acs.iecr.7b03575

Wetterling J, Mattsson T, Theliander H (2017b) Local filtration properties of microcrystalline cellulose: influence of an electric field. Chem Eng Sci 171:368-378. https://doi.org/ 10.1016/j.ces.2017.05.054

Yukawa H, Chigira H, Hoshino T, Iwata M (1971) Fundamental study of electroosmotic filtration. J Chem Eng Jpn 4:370-376

Yukawa H, Kobayashi K, Tsukuf Y, Yamano S, Iwata M (1976) Analysis of batch electrokinetic filtration. J Chem Eng Jpn 9:396-401. https://doi.org/10.1252/jcej.9.396 